\title{
Beiträge zur Käferfauna von Bogotà
}

von

Th. Kirsch in Dresden.

(Drittes Stück: Brenthiden und adelognathe Curculionen.)

Arrhenodes Goudoti: supra opacus, subtus nitidus, niger, capite, rostri parte basali, antennis apice prothoracisque vittis tribus sanguineis; elytris distincte punctato-striatis, lineis flavis sex ornatis, interstitis carinatis. - Long. 12-19 mill.

Dem A. flavolineatus Schönh. am ähnlichsten, jedoch durch Sculptur und Färbung leicht von demselben zu unterscheiden. Oben . mit Ausnahme der vorderen Rüsselhälfte matt, unten glänzend schwarz. Die Abschnürung des Kopfes am Scheitel nicht so tief ausgebuchtet, der Basaltheil nach vorn mehr verschmälert und ein Wenig kürzer, als bei flavolineatus; bei gut ausgefärbten Exemplaren nur der Scheitel, der Basaltheil des Rüssels innerhalb der beiden Kiele und die letzten Glieder der Fühler roth, das Halsschild schwarz, eine breite, den Vorderrand nicht erreichende Mittel- und zwei Seitenbinden roth. Die Flügeldecken an der Spitze abgestutzt, die Aufsenecke beim $\delta$ weniger vortretend, als bei flavolineatus, deutlich punktirt-gestreift, die $Z$ wischenräume convex, meist scharf gekielt, auf dem 2ten zwei lange, nur die Mitte und die Spitze frei lassende Linien, auf dem 3ten und 5ten je eine kurze in der Mitte, auf dem 6ten eine, der des 3ten gleichlange, im hintern Drittheil und auf dem 7 ten eine von der Schulter bis fast zur Mitte reichende Linie gelb.

A. trilineatus: supra opacus, subtus nitidus, ater, capite quadrato, remote punctulato, rostro angustiore et longiore; prothorace lateribus fere rectis, antice subito angulatim angustato, dorso 
paullo deplanato; elytris punctato-striatis, interstitiis convexiusculis, lineis tribus flavis. - Long. 22 mill.

Lacordaire trennt unter dem Namen Estenorhinus die mit einem längeren, schmäleren Kopf und vorn mehr verbreiterten Rüssel versehenen Arten von Arrhenodes ab; die obige Art bildet jedoch ein so deutliches Vermittelungsglied zwischen beiden Formen, dafs die Abtrennung, wenigstens für die amerikanischen Arten, nicht räthlich erscheint. Mit diesen Arten (forficatus, designalus etc.) hat die vorliegende gemein: den schmäleren und längeren Kopf, die somit weiter von der Basis entfernten Augen, den schmäleren und längeren Basaltheil des Rüssels; mit flavolineatus und den Verwandten: den auch am Scheitel scharf eingeschnürten Kopf (der bei designatus, monilifer etc. oben ausgeglichen und nur an den Seiten abgeselzt ist), den vorn nicht so stark verbreiterten Rüssel und die Anlage der Zeichnung.

Tiefschwarz, oben matt, unten glänzend; der Kopf fein zerstreut - punktirt, der Rüssel vor den Fühlern schwach vertieft, die Seitenkiele sehr schwach angedeutet. Das Halsschild länger als breit, oben in der Mitte der Länge nach niedergedrückt, nach der Spitze plötzlich, fast unter einem stumpfen Winkel, hinten rundlich verengt, an den Seiten fast gerade. Die Flügeldecken mit et- was nach vorn vorstehenden Schultern, an der Spitze gerade abgestutzt, die Aufsenecke beim $\sigma^{\top}$ vorgezogen, fein punktirt-gestreift, die Zwischenräume vorn leicht, hinten mehr gewölbt, der 2te bis 4te fast gekielt, auf dem 2ten zwei lange, die Mitte und die Spitze freilassende Linien, auf dem 3ten eine Linie in der Mitte gelb.

Die Beschreibung des mir in Natur nicht bekannten melancholicus $\mathbf{S c h}$. pafst in mancher Beziehung auf obigen Käfer, doch bestimmt mich die Angabe: inter antennas tubercula duo interjacente carinula abbreviata, denselben für eine verschiedene Art zu halten.

\section{Cyriodontus n. gen.}

Mas: Caput parum elongatum, antice attenuatum, postice bisinuatim abrupte impressum, angulis lateralibus parvulis acutis, collo brevi, inter oculos leviter bituberculatum.

Rosirum elongatum, parte basilari capite multo angustiore, subquadrangulari, canaliculata, inter antennas parum dilatata, parte antica longiore, angusta, apice parum subangulatim dilatata, supra plana, scubra.

Antennae ante rostri medium insertae, thoracis medium paullo superantes, articulis quatuor basalibus glabris, nitidis. 
Prothorax breviter conicus, antice utrinque pone oculos dente majore, disco antico utrinque plica elevata transversa instructus.

Elytra fortiter et gemellato punctato striata, apice truncata.

Abdomen basi sulcatum.

Pedes anteriores validiores, femoribus medio fortiter, ante apicem levius dentatis, tibiis valde curvatis, supra medium dente validiore, pedes 4 posteriores femoribus dente minore.

Fem.: Caput inter oculos distincte bituberculatum.

Rostrum parte basilari capite breviore, parte antica cylindrica nitida.

Prothorax muticus.

Pedes antici femoribus unidentatis, tibiis medio dente minore.

Wenn man mit Pascoe und Lacordaire aus der Gattung Arrhenodes den serrirostris $\mathrm{F}$ ab. als eine von den übrigen Arten durch die Form des Kopfes und Rüssels sehr abweichende ausscheidet, so ist eine andere längst bekannte Art, $\operatorname{der} A$. linealus $\mathbf{S} c h \mathrm{~h}$, , ebenfalls abzutrennen; er bildet mit Orychodes Pascoe und dem nachstehend beschriebenen Automolus eine Uebergangsgruppe zu den Belopheriden. Der vor den Fühlern dünnere und längere, an der Spitze (wenigstens im Verhältnifs zu den ächten Arrhenod.) wenig verbreiterte Rüssel mit bei Weitem kleineren Mandibeln ist allen drei Gattungen gemeinsam. Die Form des Kopfes unterscheidet dieselben leicht von einander: bei Orychodes ist derselbe stark quer, mit weit über den Vorderrand des Halsschildes vorspringenden Hinterecken, bei Cyriodontus so lang als breit, bei Automolus länger als breit. Auch die abweichende Sculptur der Flügeldecken und die anders gebildeten Vorderschienen sprechen für eine Abtrennung des lineatus S. von Arrhenodes.

C. line at us Schh. Gen. et Sp. Curcul. V.476. Long. 15-19 mill. Bei dem Schönherr unbekannt gebliebenen Männchen ist der Spitzentheil des Rüssels leicht vierkantig, oben eben und durch kleine, besonders an den Seitenkanten bemerkbare Körnchen rauh, an der Spitze etwas verbreitert, jederseits mit kleiner spitzer Ecke. Das Halsschild dicht hinter dem Vorderrande an den Seiten mit einem grofsen, frei abstehenden, nach vorn gerichteten Zahn, auf der vorderen Scheibe jederseits ein erhabenes Querfältchen. Die Vorderschenkel haben in der Mitte einen grofsen rechtwinkelig abstehenden Zahn und sind zwischen diesem und der Spitze etwas ausgehöhlt, die vordere Kante dieser Aushöhlung trägt in ihrer Mitte ebenfalls einen kleinen Zahn, die Vorderschienen sind stark gekrümmt und über ihrer Mitte innen in einen sehr kräftigen Zahn 
erweitert. An den vier hinteren Beinen sind die Schenkel mit einem kleinen spitzigen Zahn versehen.

\section{Automolus n. gen.}

Mas: Caput modice elongatum, strictura supra semicirculari a collo separatum.

Rostrum sat elongatum, parte basilari cylindrico-conica, foveola oblonga instructa, inter antennas dilatata, parte antica longiore, quadrangulari, apicem versus sensim triangulariter dilatata, apice emarginata, supra canaliculata.

Antennae ante medium rostri insertae, filiformes, thoracis basin vix attingentes, articulo primo crasso, intus paullo dilatato, 2, 3 et 4 minoribus, obconicis, sequentibus subcylindricis, ultimo longiore.

Oculi parvi, rotundati, a thoracis margine remoti, parum convexi.

Prothorax elongato.conicus, ante basin constrictus.

Elytra punctato-striata, apice truncata, angulis externis tuberculo porrecto.

Pedes anteriores longiores et validiores, femora omnia dente minuto, tibiae anticae medio intus dilatatae et dentalae, apice angulo externo dentiformi.

Fem.: Caput brevius.

Rostrum parte basilari brevissima, antica cylindrica, filiformi.

Antennae paullo breviores, basin versus insertae.

Elytra apice simpliciter truncata.

Mit Orychodes Pascoe als Uebergangsformen zwischen Arrhenodid. und Belopherid. zu betrachten. Die Gattung Automolus unterscheidet sich von Orychodes, einer den Sunda-Inseln angehörigen Gattung, durch die Form des Rüssels, die kleinen, wenig erhabenen Augen, die Sculptur und die Form der Spitzen der Flügeldekken und die gleiche Beschaffenheit der Beine in beiden Geschlechtern. Von der aus der Gruppe der Belopherid. ihr durch die Form des Rüssels zunächst verwandten Gattung Ectocemus Pascoe ist sie durch die verhältnifsmäfsig viel kürzeren Fühler sehr verschieden.

A. pictus (Dej.): niger, glaber, opacus, verticis macula, prothoracis dorso, vitta laterali arcuata, prosterni, metasterni et abdominis medio clavisque femorum rufo ferrugineis, elytrorum lineolis duabus basalibus, una apicali fasciisque duabus (anteriore obliqua) flavis. - Long. 8-22 mill. 
Diese schön gezeichnete Art ist maltschwarz, nur der Rüssel vor den Fühlern und die Unterseite glänzend. Die dreieckige Verbreiterung des Rüssels bei sehr kleinen Männchen wenig in die Augen fallend. Das Halsschild gestreckt kegelförmig, vor der Basis eingeschnürt und mit schmalem Querwulst, beim Männchen etwas länger und schmäler, als beim Weibchen, eine breite, den Vorderrand nicht erreichende Längsbinde auf dem Rücken und eine schmälere gekrümmte Binde jederseits rostroth; mitunter fliefst die Seitenbinde vor der Mitte in die Rückenbinde über, so dafs von der schwarzen Färbung jederseits nur ein länglicher Basalfleck und ein kleinerer am Vorderrande übrig bleiben. Die Flügeldecken schwach gewölbt, an der Spitze abgestutzt, die Aufsenecke beim $\sigma^{\top}$ mit einem stumpfen, nach rückwärts gerichteten Höcker, punktirt-gestreift, die Zwischenräume wenig gewölbt, mattschwarz, an der Basis der 2te Zwischenraum in längerer, der 4te in kürzerer Ausdehnung (bei grolsen $\delta$ milunter auch der 3 te), vor der Mitte eine schräge Binde aus 7 Längslinien gebildet, deren innerste auf dem 2 ten $Z$ wischenraum, hinter der Mlitte eine gerade Querbinde ebenfalls aus 7 Längs-

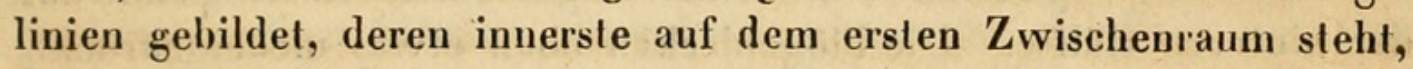
und der 2te Zwischenraum vor der Spitze gelb. Auf der Unterseite die Mitte der Vorderbrust, der Hinterbrust und der ersten beiden Hinterleibsringe, sowie die Keulen der Schenkel mit Ausnahme ihrer Spitzen rostroth.

Claeoderes bivittalus: varietas C. mexicani Schh.; differt rostro distinctius sulcato, elytrorum linea marginali deficiente et tibiis anticis maris extus infractis. - Long. ơ 33 mill., +26 mill.

Schönherr stellt diese Form als Varietät zu mexicanus, erwähnt aber der abweichenden Bildung der männlichen Vorderschienen nicht, die für die Selbstständigkeit der Art zu sprechen scheint. Die Rüsselfurche ist tiefer und reicht weiter nach dem Scheitel hinauf, auch ist der Rüssel hinter den Fühlern, im Verhältnifs zu dem Theil vor denselben, dicker als bei mexicanus; auf den Flügeldecken sind die Punkte der Streifen entschieden gröber, nur der 2te Zwischenraum von der Basis bis fast zur Spitze gelb, der 8te durchaus schwarz. Die männlichen Vorderschienen sind zwischen Basis und Milte, an derselben Stelle, wo der Innenrand eckig hervortritt, am Aufsenrande winkelig eingeknickt.

Brenthus armillal us: niger, subnitidus, glaber, prothorace basi obsolete canaliculato, elytris subdeplanatis, fortiter striato-punctatis, interstitiis convexis, lateraliter subcostatis, elytrorum maculis qualuor, femorum clavis, mesosterni medio, metasterno abdomi- 
nisque basi rufosanguineis, femoribus dente minore. - Long. $\delta 30$ mill., 우 25 mill.

B. armillatus Chevr. i. litt.

Mas: rostro canaliculato, antice dilatato, elytrorum interstitio nono postice costiformi, ad apicem dilatato et acuminato.

Fem.: rostro postice canaliculato, antice cylindrico, elytris apice recte truncatis.

Var. Maculis elytrorum confluentibus.

B. erythromerus Dej. i. coll.

B. rufopictus Chevr. i. coll.

In die von Lacordaire an die Spitze der Gattung gestellte Gruppe von calcar, Pyctes etc. gehörend.

Schwarz, schwach glänzend, glałt; der Kopf vor der Abschnürung des Halses leicht querwellig, mit einem trübrothen Fleck auf dem Scheitel; der Rüssel beim $\delta$ über die ganze Länge bis zur Verbreiterung an der Spitze gerinnt, beim ㅇ nur im Basaltheil und zwischen den Fühlern, vorn stielrund. Das Halsschild kegelförmig, vor der Basis abgeschnürt, mit einer eingeschnittenen Längslinie auf der hinteren Hälfte. Die Flügeldecken oben etwas niedergedrückt, stark punktirt-gestreift, mit gewölbten, den Seiten zu fast rippig erhabenen $Z_{w}$ ischenräumen, deren 9 ter beim $\delta$ hinten verbreitert ist und als ausgezogene stumpfe Spitze hervortritt, so dafs die Flügeldecken zusammengenommen an der Spilze in einem Bogen ausgerandet erscheinen, beim $ᄋ$ ist die Anlage zwar eine ähnliche, doch tritt die durch den 9 ten $\mathrm{Z}$ wischenraum gebildete Aufsenecke weniger hervor. Die 4 rothen Flecke der Flügeldecken befinden sich der 1ste auf dem 2ten und 3ten Zwischenraum an der Basis, der 2te auf dem 4ten bis 7 ten vor der Mitte, der 3te auf dem 1sten bis 4ten dicht binter der Mitte und der 4te auf dem 1sten und 2ten vor der Spitze. Auf der stark glänzenden Unterseite ist die Mitte der Mittelbrust, die ganze Hinterbrust sowie die ersten beiden Hinterleibssegmente (mit Ausnahme der Ränder) roth. Die Hinterschenkel erreichen die Spitze des 2ten Hinterleibssegments, die Schenkelkeulen roth, sämmtlich mit einem kleinen dornartigen Zahn versehen.

Bei der unter dem Namen eriythromerus Dej. in den Sammlungen verbreiteten Varietät ist der 3te $\mathrm{Z}$ wischenraum bis zum 2ten oder auch selbst bis zum 3ten Flecken roth.

Die Stammform ist mir aus Venezuela, die Varietät aus Bogotà zugekommen. 
B. unident at us: niger, subnitidus, glaber, rostro antice prothoraceque elongato-conico canaliculatis, elytris apice singulatim rotundatis, grosse punctato - striatis, interstitiis secundo et tertio interrupte flavo-lineatis, femoribus unidentatis. - Long. 33-39 mill.

In die 2te Gruppe Lacordaire's in die Nähe von bidentatus Schh. gehörend. Schwarz, schwach glänzend, glatt; der Rüssel beim $\delta$ vorn etwas verbreitert, vor den Fühlern mit tiefer Mittelrinne, die sich bei sehr grofsen Exemplaren auch auf den Basaltheil fortsetzt; der Kopf vor der Einschnürung des Halses mit stumpfen Ecken. Das Halsschild verlängert kegelförmig, oben der Länge nach eingedrückt, mit tief eingeschnittener Mittellinie. Die Flügeldecken an der Spitze einzeln abgerundet, grob punktirt - gestreift, der 9te Zwischenraum hinten auffallend verdickt, um die Spitze herum bis zur Naht fortlaufend; die gelbe Zeichnung der Flügeldecken besteht in zwei fast gleichlangen Linien auf dem 2 ten $\mathrm{Zwi}$ schenraum, einer etwas längeren an der Basis und einer viel kürzeren hinter der Mitte (neben der von den Linien des 2ten Zwischenraumes frei gelassenen Stelle) auf dem 3ten $Z$ wischenraum, und bei grofsen Stücken einer kurzen Linie auf der Basis des 4ten Zwischenraumes. Die Schenkel gezähnt, die hintersten nicht ganz die Spitze des 2ten Abdominalsegments erreichend.

Der Käfer ist unter dem Namen interruptus Dej., crocodilus Chevr. in den Sammlungen verbreitet, ich zog jedoch den ihm von H. Jekel beigelegten Namen vor, da er die Beziehungen andeutet, in denen er zu dem der Zeichnung nach sehr ähnlichen bidentatus Schb. steht.

\section{B. canaliculatus Fab.}

Var. insubidus: differt statura multo minori, elytris pro latitudine multo brevioribus, cauda marum valde abbreviata, abdominis apice grossius punctata. - Long. 13-19 mill.

In der Zeichnung und Sculptur der Oberseite ganz mit der Stammform übereinstimmend, jedoch wenig über halb so grofs; durch die relativ breiteren Flügeldecken und überdies durch die sehr verkürzten, etwa ein Viertel der Flügeldeckenlänge betragenden Spitzen der Männchen eine abweichende Form darbietend. Unterseits sind die drei mir zugekommenen Stücke auf dem letzten Abdominalsegment gröber punktirt als bei canaliculatus. 
Hyps ometopus nen.

Caput transversum, parum convexum.

Rostrum capite parum longius, medio angustatum, antice dilatatum, apice emarginatum, subtus triangulariter impressum, obsolete quadrangulare, scrobes antennarum fere superi, lati, mox subtus curvati, ab oculis remoti.

Oculi laterales, rotund, fortiter granulati.

Antennae terminales, thoracis medium attingentes, scapo recto, apice paullo incrassato, oculos superante, funiculi articulis duobus basalibus elongatis (secundo primo longiore), 3 et 4 brevissime obconicis, reliquis moniliformibus, clava ovali acuminata.

Prothorax subquadratus, antice parum angustatus, basi truncatus, apice rotundatus, lateribus leviter ampliatis.

Scutellum parvum, transversum, triangulare.

Elytra ovalia, prothoracis basi vix latiora, conjunctim subemarginata, lateraliter inflexa, apice angustata, dorso antico parum convexa, postice fortiter declivia.

Pedes: femora dente minuto armata, antica fortius clavala, tibiae anticae, reliquis longiores, intus nodulosae, apice curvatae, angulo interno acuminato, posticae corbulis (corbeilles Lacord.) apertis nec cavernosis, unguiculis liberis.

Bei dem Mangel aller schneidenden Unterschiede zwischen den Brachyderiden und Naupactiden ist es, da bis jetzt in beiden Gruppen jede Analogie für die Rüsselbildung der beschriebenen Gattung fehlt, zweifelhaft, wohin dieselbe zu stellen. Schönherr hat den Käfer, durch den allgemeinen Habitus geleitet, als einen Sciaphilus angesehen, Jekel hat ihn, dem Bau der Beine das gröfsere Gewicht beilegend, zu den Naupactiden gestellt.

Der Kopf quer, am Scheitel wenig gewölbt, auf der Stirn leicht quer niedergedrückt, die Augen rund, grob granulirt; der Rüssel etwas länger, als der Kopf, in der Mitte verengt, an der Spitze wieder verbreitert, zwar vierkantig, aber die oberen Kanten einander genähert, so dafs die beiden Seitenflächen, schief nach unten abfallend, von oben ganz sichtbar sind und die Fühlergruben auf der Oberseite zu liegen scheinen; dieselben biegen sich dann, von den Augen entfernt bleibend, schnell nach unten; die Spitze des Rüssels ist vorn ausgerandet, die Unterseite desselben mit zwei tiefen, hinten sich vereinigenden Furchen, der Raum zwischen denselben ebenfalls etwas vertieft. Die Fühler bis in die Mitte des Halsschildes reichend, das 1ste Glied der Geifsel dicker und kürzer als das 2te. Das Halsschild so lang als breit, an der Basis ge- 
rade, an den Seiten und am Vorderrande gerundet erweitert. Das Schildchen klein, quer dreieckig, dicht gelblich - weifs beschuppt. Die Flügeldecken oval, an der Basis kaum breiter als das Halsschild, die Schultern etwas vorstehend, an den Seiten sanft gerundet, hinten verengt, an der Spitze zusammen stumpf abgerundet, oben flach gewölbt, die Seiten steil, nach hinten fast kantig abfallend. Die Vorderhüften einander berührend, die mittleren durch einen schmalen Brustkiel getrennt, die Schenkel (die vordersten am meisten) keulig verdickt, die Vorderschienen länger als die übrigen, an der Spitze nach innen gekrümmt, auf der Innenseite mit kleinen Knötchen besetzt, die innere Endecke zugespitzt, die Klauen kräftig und fein.

H. inquinatus: obovatus, niger, crusta terrea oblectus (rostri apice nitida excepta) antennis ferrugineis, prothorace granulato, sparsim breviter setuloso, elytris punctato-striatis, interstitiis parum convexis, breviter setulosis. - Long. 7 mill.

Sciaphilus inquinatus $\mathrm{S} c h \ddot{n} \mathrm{nh}$. i. coll.

Hypsometopus sus Jekel Brit. Mus.

Schwarz, mit einer graubräunlichen erdigen Kruste auf der Oberseite mehr, auf der unteren weniger bedeckt, die nur die glänzend schwarze Spitze des Rüssels frei läfst. Das Halsschild grobkörnig, mit kurzen niedergeneigten Börstchen besetzt, die Flügel-

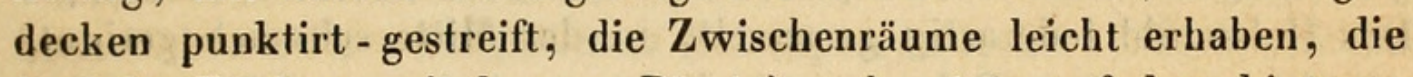
fünf des Rückens mit kurzen Börstchen besetzt, auf dem hinteren ziemlich steil abfallenden Theil die Nahtgegend erhabener.

Amphideritus rugicollis: elongalo-obovatus, niger, antennis pedibusque fusco-ferrugineis, fronte oblique striata, medio usque ad verticem canaliculata, rostro antice ruditer punctato et sparsim squamoso; prothorace fortiter granulato-rugoso, medio canaliculato; elytris punctato-striatis, albido pubescentibus, interstitiis convexiusculis, pilis griseis, seriatis, erectis; pectoris lateribus squamulis subargenteo micantibus dense tectis. - Long. 6 mill.

In der Form etwas gestreckter, namentlich die Flügeldecken verhältnifsmäfsig viel schmäler als bei vilis Schh. Schwarz, die Fühler und Beine dunkel rostfarben, die Stirn mit einer scharf eingeschnittenen, bis auf den Scheitel reichenden Mittelrinne und jederseits derselben mit schiefen, nach vorn convergirenden Längsrunzeln, der Rüssel an der Basis etwas quer niedergedrückt, vorn in der Mitte leicht gekielt, dicht grob punktirt, jeder Punkt mit einer grünlich-weifsen Schuppe besetzt. Das Halsschild so lang als breit, fast cylindrisch, an den Seiten ein Wenig gerundet, an der 
Basis erhaben gerandet, grob körnig gerunzelt, in der Mitte mit einer seichten Längsrinne. Die Flügeldecken doppelt so lang als das Halsschild, mit schwach gerundeten Seiten, grob punktirt gestreift, auf der vorderen Hälfte, von der Seite gesehen, leicht querrunzlig,

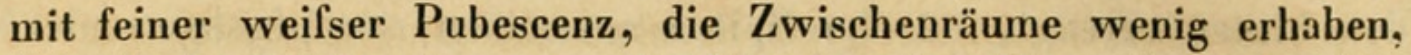
je mit einer Reihe langer, aufrechter, greiser Haare besetzt. Die Unterseite weifs pubescent, die Seitenstücke der Brust mit runden, silberweifs schimmernden Schuppen dicht besetzt.

A. squamosus: elongato-obovatus, fusco-ferrugineus, fronte dense subtiliterque oblique striala, canaliculata, rostro basi profunde sulcato, medio transversim impresso, antice subplano, sparsim punctato et squamoso; prothorace coriaceo, subcanaliculato, pube brevi, albida, lateraliter squamulis submetallicis interjectis; elytris punctato-striatis, griseo squamosis, squamis versus latera majoribus, densioribus et magis cretaceis, interstitiis planis, pilis albidis et nigris erectis seriatis; pectore femoribusque posticis ante apicem dense albido squamosis. - Long. 6 mill.

Von der Gestalt und Gröfse der vorhergehenden Art; gleichmäfsig dunkel rothbraun, die Stirn bis zum Scheitel mit einer Längsrinne und leichten, nach vorn zusammenneigenden Längsrunzeln, der Rüssel an der Basis tief gefurcht, vor den Fühlern deutlich quer eingedrückt, an der Spitze zerstreut-punktirt und beschuppt. Das Halsschild lederartig gerunzelt, in der Mitte schwach gerinnt, mit feiner weifser Pubescenz bedeckt, zwischen welcher an den Seiten weifsliche, metallisch - glänzende Schuppen eingestreut sind. Die Flügeldecken seicht und entfernt punktirt-gestreift, graulichweifs beschuppt, die Schuppen nach den Seiten zu gröfser, dichter

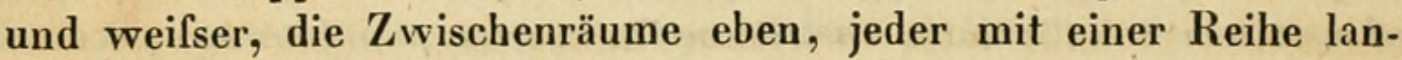
ger, weifser und schwarzer Haare besetzt. Die Brust und die hintersten Schenkel vor der Spitze dicht silberweifs beschuppt.

\section{Mimographus Schh.}

Lacordaire hat darauf hingewiesen, in wie naher Verwandtschaft diese Gattung zu Amphideritus Schh. steht, und dafs sie sich kaum durch etwas Anderes, als die bemerkbar weiter von der Spitze des Rüssels entfernt eingefügten Fühler unterscheide. Allein auch dieses Merkmal erscheint bei dem mir reichlich vorliegenden Material nicht ganz zuverlässig und zweifellos entscheidend; vielmehr sind es habituelle Merkmale, die mich davon abhalten, die nachfolgenden Arten zu Amphideritus zu stellen. Die gewölbteren Augen, der im Verhältnifs zur Breite längere Rüssel, das relativ 
schmälere Halsschild, die etwas längeren Hinterschienen, besonders aber die stumpfeckiger vortretenden Schultern der Flügeldecken geben diesen Arten einen, wenigstens von den 3 mir bekannten Amphideritus-Arten abweichenden Habitus.

Die Artunterscheidung ist in dieser Gattung ziemlich schwie. rig, da die Sculptur wenig Anhaltepunkte bietet und die Färbung innerhalb der Art oft sehr variirt. Alle Arten haben auf dem Rüssel eine eingedrückte Längslinie, das Halsschild fast cylindrisch ( $\left.\sigma^{\top}\right)$ oder schwach gerundet (\%), hinter dem Vorderrande schwach eingeschnürt, die Flügeldecken punktirt-gestreift.

$\boldsymbol{A}$. Schenkel ungezähnt.

a. Mit langen Haaren am Vorderrande des Halsschildes und

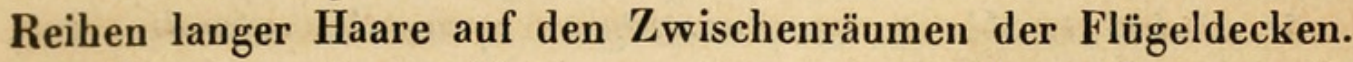

M. amandus: oblongo-ovatus, niger, dense fusco, griseo, ferrugineo vel ochraceo squamosus, squamulis capitis thoracisque angustis, elytrorum obovatis, vittis duabus prothoracis e squamulis obovatis, maculis duabus elytrorum fasciague postica obligua albis. — Long. 9-10 mill.

Variat signaturis magis minusve obsoletis.

Buquet i. litt.

Der Rüssel ist vor den Fühlern mit runden grünlichen, hinter denselben, sowie Stirn, Scheitel und Halsschild mit schmalen, grauen, bräunlichen oder ocherfarbenen Schuppen bedeckt. Das Halsschild beiderseits mit einer aus rundlicheren weifsen Schuppen gebildeten Längsbinde, die zuweilen nur noch an der Basis und am Vorderrande angedeutet, mitunter auch ganz verloschen ist, und mit kurzer, nach vorn gerichteter, zerstreuter, je nach der Farbe des Schuppenkleides hellerer oder dunklerer Behaarung. Die Flügeldecken mit verkehrt-eiförmigen, nach den Seiten zu und auf den weifsen Zeiehnungen rundlicheren Schuppen; die Grundfarbe des Schuppenkleides in denselben Nüancen variirend, wie auf dem Halsschilde; die weifsen Zeichnungen sehr veränderlich, bald bestehen sie aus einer welligen Binde, die an der Naht beginnt und schief nach vorn und aufsen gerichtet über der Spitze des ersten Hinterleibssegments endet, und zwei kleinen Flecken, von denen einer auf dem 3ten und 4 ten, der andere auf dem 7 ten $Z$ wischenraume etwas vor der Mitte der Flügeldecken stehen, bald fliefsen diese beiden Flecke zusammen und der äufsere dehnt sich bis zum Seitenrand und bis zur Schulter aus, bald löst sich die hintere Binde in kleine Flecken auf, bald zieht sich dieselbe von der Naht zurück und es bleibt endlich nur noch ein kleiner Fleck an den Seiten übrig. Häufig 
stehen die Schuppen vor der Schrägbinde etwas zerstreuter und es bildet sich dadurch ein dieselbe schärfer abgränzender, dunklerer Fleck. Die ganz hell gefärbten Exemplare, deren Zeichnungen kaum angedeutet sind (die Jekel als var. pallida in litt. bezeichnet), halle ich für sehr junge Individuen. Die in Längsreihen auf den Zwischenräumen stehenden Haare entspringen aus einem unbeschuppten schwarzen Fleckchen und sind dem Schuppenkleide analog gefärbt. Die Unterseite ist auf der Brust, an den Seiten des Halsschildes und des Hinterleibes dicht mit runden, weifsen, silber- oder perlmutterglänzenden, auf der Mitte des Hinterleibs mit zerstreuten, schmalen, weifsen oder graulich - weifsen (bei 1 Exemplar grünlichen) Schuppen bedeckt. Die Beine dicht beschuppt und behaart.

M. Jekelii: oblongo-ovatus, niger, squamulis rotundis, griseo albis, certo silu pallide roseis, vestitus; prothorace disco postico levissime carinulato; elytris fusco-testaceis, versus humeros nigricantibus, macula communi fere ancoraeformi. - Long. 9 mill.

Der ganze Käfer mit runden, graulich - weifsen Schuppen bedeckt, die, in schräger Richtung gesehen, besonders an den Seiten der Flügeldecken und auf der Unterseite blafs rosenroth schimmern. Auf dem Kopfe und Halsschilde stehen die Schuppen einzeln, so dafs man jede derselben von der schwarzen Grundfarbe umgeben sieht. Das Halsschild auf der hinteren Hälfte der Scheibe mit einem deutlichen, niedrigen, nicht bis zur Basis reichenden Längskielchen. Die bräunlich-gelben, nur in der Schultergegend geschwärzten Flügeldecken ganz dicht beschuppt, nur auf den $Z_{w i-}$ schenräumen mit Reihen nackter Fleckchen, aus denen die blafsgelben Haare entspringen, eine gemeinschaftliche Binde längs der Naht bis hinter die Mitte, an welche sich in der Mitte jederseits ein nach vorn offener Bogen anschliefst und eine kleine Stelle jederseits vor dem Spitzenhöcker sparsamer beschuppt. Die Beine, namentlich die Schienen, mit etwas länglicheren Schuppen, greis behaart.

Zu Ehren des Herrn Jekel in Paris benannt, dem ich mich für viele Mittheilungen über diese Familie besonders verpflichtet fühle.

M. viridanus: oblongus, niger, squamulis rotundis viridibus vestitus, prothorace dimidia postica leviter canaliculato, elytris fascia obliqua flava pone medium. - Long. 10 mill.

In der Form der Schuppen mit dem Vorigen, in der Zeichnung der Flügeldecken mit amandus übereinkommend. Kopf und Halsschild nicht sehr dicht mit grünen, um die Augen und nach den Vorderhüften zu mehr ins Gelbliche ziehenden Schuppen bedeckt. 
Das Halsschild auf der hinteren Hälfte mit einer seichten Längsrinne und mit zerstreuten, kurzen, schwarzen, aus nackten Fleckchen entspringenden Haaren. Die Flügeldecken dichter mit runden grünen Schuppen bedeckt, die unter dem Schulterhöcker und vor der Spitze mehr mit gelben untermischt sind, und auf den Zwischenräumen nur eine Reihe kleiner Fleckchen frei lassen, aus denen die schwarzen Haare entspringen; die gelbe Schrägbinde ist in ihrer Mitte durch schwarze Schuppen unterbrochen und nach vorn durch eben solche unregelmäfsig begränzt. Die Unterseite nicht sehr dicht mit grünen, an den Seiten der Brust und des Hinterleibes gelben, mitunter goldglänzenden Schuppen bedeckt.

M. lugens: oblongus, niger, squamulis rolundis, obscuris, sparsim obtectus, rostro lateribus, elytris interstitio sexto pone humerum, fascia obliqua pone medium, inde sutura usque ad apicem maculaque parva inter fasciam et apicem viridi-aureo squamosis. Long. 10-11 mill.

Das allgemeine Schuppenkleid von so dunkler Farbe, dafs der Käfer dem blofsen Auge fast nackt erscheint; unter der Loupe lassen sich jedoch dunkel blaugraue Schuppen, die an den Seiten und vor der Spitze der Flügeldecken dichter stehen, erkennen. Der Rüssel an den Seiten, über und unter den Fühlergruben goldgrün beschuppt, auf der Oberseile wie Stirn, Scheitel und Halsschild zerstreut greis-behaart und mit kleinen, runden, von dem Grunde wenig abstechenden Schuppen besetzt. Das Halsschild an der Basis neben den Hinterecken mit einigen grünen Schuppen, die langen Haare am Vorderrande schwarz. Die Flügeldecken etwas glänzend, da vermöge der sparsamen Beschuppung der Untergrund überall durchscheint; die goldgrünen Zeichnungen bestehen in einem kurzen Strich auf dem 6ten $Z$ wischenraum hinter der Schulter, einer Schrägbinde von der Naht nach aufsen und vorn, über der Spitze des ersten Hinterleibssegments endigend, einem Fleckchen in der Gegend des Spitzenhöckers und der Naht von der Binde bis zur Spitze; die Zwischenräume mäfsig gewölbt, mit einer Reihe dunkelbrauner Haare besetzt, die Punkte der Streifen viel schmäler als

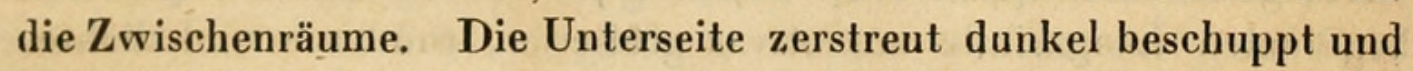
greis behaart. Die vordersten Beine schwarz, an den 4 hinteren die untere Hälfte der Schenkel und die Schienen hellbraun.

M. moestus: oblongus, niger, squamulis rotundis, obscuris, sparsim obtectus, elytris fasciis duabus obliquis, silaceo squamosis; prothorace granulato - rugoso, medio canaliculato, - Long. 7-8 mill. 
Variat maculis elytrorum iribus, una ante medium, duabus pone medium, oblique positis.

Mit eben solchen runden, dunkeln, zerstreut stehenden Schuppen bekleidet, wie der Vorige. Der Rüssel um die Augen, an den Seiten und unten weifs beschuppt, oben, wie Stirn und Scheitel, aufser der dunkeln Beschuppung noch mit kurzen, braunen Haaren besetzt. Das Halsschild an den Seiten etwas mehr gerundet, als gewöhnlich, unregelmäfsig körnig - runzelig, mit einer Längsrinne, die auf der Mitte ein kurzes Längskielchen einschliefst, in den Vertiefungen dunkel beschuppt und mit kurzen braunen Haaren besetzt, die längeren Haare des Vorderrandes schwarz. Die Flügeldecken tief punktirt-gestreift, die etwas queren Punkte der Streifen fast so breit als die gewölbten $Z_{w}$ ischenräume, diese mit Längsreihen brauner Haare; die zerstreuten, sehr kleinen, dunkeln Schuppen nur nach den Seiten hin mit einzelnen grünen gemischt; die beiden schiefen, weder die Naht noch den Seitenrand berührenden Binden aus gröfseren, runden, röthlich grauweifsen Schuppen gebildet und in ihrer Ausbildung variabel, an einem Stücke nur noch durch 3 Fleckchen angedeutet, einer vor der Mitte auf dem 2ten und zovei hinter der Nitte auf dem 2ten und 6ten Zwischenraume, der äufsere mehr nach vorn. Die Unterseite mit zerstreuten, haarförmigen, greisen, an den Seiten der Brust mit gröfseren, runden, grünlich und röthlich schimmernden Schuppen besetzt. Die vordersten Beine schwarz, die vier hinteren röthlich braun.

M. argutulus: elongato-oblongus, niger, viridi-squamosus, squamis elytrorum magnis, rotundis, densis, sub aureo-micantibus. - Long. 8-9 mill.

Buquet in litt.

Schmal, gestreckt, schwarz; der Kopf an den Augenrändern, den Seiten und unten mit länglichen, dichten, goldgrün glänzenden, oberseits mit sehr zerstreuten, kleinen, fast haarförmigen, grünlichen Schuppen besetzt. Das Halsschild wenig breiter als der Kopf, leicht runzelig, mit kurzer dunkler Behaarung und kleinen, länglichen, grünen Schuppen bestreut, und jederseits einer wenig scharf begränzten Längsbinde aus etwas gröfseren, runderen und dichter stehenden Schuppen gebildet. Die Flügeldecken schmäler als bei allen vorhergehenden Arten, fast parallel, gleichförmig dicht mit grofsen, runden, grünen, nach den Seiten zu goldgrün glänzenden Schuppen bedeckt, die nur die Punkte der Streifen und auf den Zwischenräumen Reihen kleiner Flecke frei lassen, aus denen die langen, dunkeln Haare entspringen. Die Schuppen der Unterseite 
ziemlich dicht, rundlich, weifs, perlmutterglänzend oder goldgrün, nach hinten schmäler und zerstreuter. Die vordersten Beine schwarz, an den vier hinteren die Schenkel und Schienen dunkelrothbraun, die Tarsen schwarz.

M. ardosiacus: elongato-oblongus, niger, squamulis angustis, minutissimis, viridibus, adspersus, pectoris lateribus utrinque vitta saepe bene determinata squamarum majorum subrotundarum, alba, margaritacea vel subaureo-viridi. - Long. 7-9 Mill.

Jekel in litt.

Dem argutulus sehr ähnlich, doch etwas gedrungener gebaut (die Flügeldecken im Verhältnifs zur Länge bemerkbar breiter), meist auch kleiner (unter einigen 20 Exemplaren nur eins von der Länge des Vorigen) und durch die Form der Schuppen sicher von demselben zu unterscheiden. Das allgemeine Schuppenkleid des Käfers ist aus so kleinen, schmalen (auf dem Kopfe und Halsschilde haarförmigen) zerstreuten, grünen Schüppchen gebildet, dafs derselbe durch den überall hervortretenden, schwarzen Untergrund ein schiefergraues und bei unausgefärbten Exemplaren livides Aussehen erhält. Die kurze Behaarung des Kopfes und Halsschildes greis, die langen Haare am Vorderrande des letzteren und auf den Zwischenräumen der Flügeldecken bräunlich gelb. Das Halsschild etwas gröber runzelig körnig, die glänzenden Körnchen erhabener als beim Vorigen. Auf der Unterseite jederseits eine meist scharf begränzte, von den Augen bis auf den 2ten Hinterleibsring reichende Binde aus gröfseren, runderen, weifsen, perlmutter oder fast goldgrün glänzenden Schuppen. Die Vorderbeine, an den vier hinteren die Schenkelkeule und die Tarsen schwarz, Schenkelwurzel und Schienen dunkelbraun.

b) Der Vorderrand des Halsschildes ohne, die $Z$ wischenräume der Flügeldecken aber mit Reihen längerer Haare.

M. micans: oblongus, niger, squamulis albis, roseo-micantibus, densius obtectus, capite prothoraceque vix pubescentibus, elytris maculis obsoletis denudatis subseriatis. - Long. 9 mill.

Von der Länge des argutulus, jedoch bedeutend breiter. Schwarz, ziemlich dicht mit grofsen, runden, weifsen, rosig, auf den Schenkeln grün glänzenden Schuppen bedeckt. An den Fühlern sind das 3te bis 7 te Geifselglied etwas mehr gestreckt, als bei den bisher aufgeführten Arten. Kopf und Halsschild mit sehr zerstreuten, kurzen, dicken, niederliegenden, nur bei starker Vergröfseruug zwischen der Beschuppung sichtbaren, greisen Härchen. Das Halsschild um ein Viertel breiter als der Kopf, nach hinten kaum ver- 
engt. Die Flügeldecken anderthalb Mal so breit als das Halsschild und $2 \frac{1}{4}$ Mal so lang als über die Schultern breit, auf den $Z_{\text {wischen- }}$ räumen mit Reihen weifser Haare, an deren Basis nur eine Schuppe fehlt und mit vier wenig auffallenden Reihen unregelmäfsig von Schuppen entblöfster, schwarzer Fleckchen. Dí Beine rothbraun, nur die Keulen der Vorderschenkel und die Tarsen fast schwarz.

c) Weder am Vorderrande des Halsschildes, noch auf den Zwischenräumen der Flügeldecken mit längeren Haaren.

Die beiden hierher gehörigen Arten haben den Fühlerschaft nach der Basis zu mehr verdünnt, das 3te bis 7te Glied der Geissel mehr gestreckt und die Keule etwas schmäler und länger als die vorhergehenden Arten, kommen aber in allen anderen Beziehungen so sehr mit ihnen überein, dafs sie wohl dieser Gattung eingereiht werden müssen.

M. rufipes: oblongus, breviter pubescens, niger, prothorace elytrisque fuscis, antennis pedibusque rufis; thorace lateribus rotundatis, vitta utrinque marginali flava, elytris vitta lata discoidali flava. - Long. 8 mill.

Durch die ganz rothen, nicht beschuppten Beine von allen übrigen Arten zu unlerscheiden. Der Kopf und die Unterseite schwarz, mit zerstreuten, kurzen, greísen, mitunter auch kupferig glänzenden Schuppenhaaren besetzt. Das Halsschild an den Seiten gerundet, nach hinten mehr verengt, als gewöhnlich, auf der Scheibe beiderseits etwas gewölbt, daher längs der Mitte leicht niedergedrückt, braun, mit zerstreuten greisen Schuppenhaaren und einer gelben Längsbinde am äufsersten Seitenrande. Die Flügeldecken fast $2 \frac{1}{2}$ Mal so lang, als breit, mit einer ziemlich dichten, nach hinten mehr abstehenden Pubescenz bedeckt; die gelbe Längsbinde reicht von der Basis bis zur Spitze und vom 2ten bis zum 9ten, binter der Mitte nur bis zum 7 ten $\mathrm{Z}$ wischenraum, läfst an der Basis den 4ten und 6ten, dicht hinter der Mitte den 3ten Zwischenraum und die Gegend des Spitzenhöckers frei, und ist aus dicken, unordentlich über einander liegenden, gelben Schuppen und auf den Zwischenräumen ziemlich dicht stehenden, etwas aufgerichteten, gelben Schuppenhaaren gebildet.

M. suturalis: oblongus, niger, breviter pubescens, antennarum scapo tenuissimo ferrugineo; prothorace lateribus parum rotundatis, viridi-griseo squamosis, elytris (sutura margineque laterali exceptis) viridi-griseo squamosis. - Long. $7 \frac{3}{4}$ mill.

Mit Ausnahme der Fühler und Beine ganz schwarz; auf dem Kopfe mit kleiven, weifslichen, um die Augen und an den Seiten 
dichter stehenden Schuppen und Härchen, die Fühler rostbraun, nur die Spitze des ungewöhnlich dünnen Fühlerschaftes und die Keule schwarz. Das Halsschild gleichmäfsig gewölbt, von der Basis bis zur Mitte parallel, von da nach vorn in flachem Bogen um ein Viertel verengt, wie der Kopf bekleidet und an den Seiten grünlichgrau beschuppt. Die Flügeldecken fast $2 \frac{1}{2} \mathrm{Mal}$ so lang als breit, mit kurzer, greiser, nach hinten dichterer Pubescenz und niederliegenden, grünlich-grauen Schuppen und ebenso gefärbten, etwas aufstehenden, dicklichen Schuppenhaaren, die nicht blos auf die Zwischenräume beschränkt sind, bekleidet; die Naht bis zur Wölbung, sowie der Seitenrand erscheinen dunkler, da sie mit zerstreuteren, kleineren Schüppchen besetzt sind, ebenso die Unterseite mit den Beinen, von denen die vordersten schwarz, die vier hinteren rothbraun und nur an den Schenkelkeulen und Tarsen schwarz sind.

B. Vorderschenkel gezähnt.

M. dentipes: oblongo-ovatus, niger, squamulis cervinis dense vestitus; prothorace subcylindrico, elytris fusco-variegatis, interstitiis convexis hinc inde squamulis piliformibus albis seriatis, femoribus anticis denticulo armatis. - Long. 4 $\frac{1}{2}-6$ mill.

Die Flügeldecken verhältnifsmäfsig kürzer und breiter als bei allen anderen Arten, daher gedrungener erscheinend. Der ganze Käfer ist dick beschuppt, nur an der Spitze des Rüssels stehen weifsliche, zerstreutere Schuppen, so dafs die Grundfarbe sichtbar wird. Auf dem Kopfe reicht die eingeschnittene Mittellinie bis zum Scheitel; das Halsschild ist vorn kaum verengt, an den Seiten nicht gerundet, zwischen der an der Basis weifslicheren Beschuppung bleiben kleine Punkte und wurmartig gekrümmte Linien frei; manchmal sind zwei kleine braune Flecken an der Basis neben den Hinterecken vorhanden, manchmal auch noch die Mittellinie braun gefärbt. Die Flügeldecken kaum $1 \frac{3}{4} \mathrm{Mal}$ so lang als breit, mit stumpfeckig vorragenden Schulterbeulen und beim $\sigma^{\top}$ geraden, beim 우 schwach gerundeten Seiten, an der Basis einzeln fast stumpfeckig vorgezogen, punktirt-gestreift, mit schwach gewölbten Zwischenräumen, auf dem Rücken rehfarben, nach den Seiten zu weifslich beschuppt; vor der Mitte eine schräge, nach der Schulterecke zeigende Binde, hinter der Mitte eine dreieckige, mit der Spitze nach vorn gerichtete Makel und der Spitzenhöcker dunkelbraun beschuppt; aufserdem auf den weifslicheren Stellen mit hellen, ein Wenig aufstehenden, gereihten Schuppenhaaren besetzt. Die Unterseite mit den Beinen bis zum Krallengliede dicht mit weifslichen Schuppen 
bedeckt und mit zerstreuten, am Körper mehr anliegenden, an den Beinen mehr abstehenden Schuppenhaaren besetzt. Die Vorderschenkel in beiden Geschlechtern deutlich gezähnt.

Es mag dem einstigen Monographen dieser Gruppe überlassen bleiben, ob nicht auf die vorstehende Art, sowie auf Naupactus pavidus Klug, welcher ein ebenso kurzes zweites Geifselglied (abweichend von allen ächten Naupact.) besitzt, eine besondere Gattung zu gründen sein dürfte, die sich unmittelbar an Naupactus anreihen müfste.

Hadromerus ruficrus: oblongus, niger, antennis, femoribus articuloque tarsorum ultimo fusco-ferrugineis; squamulis piliformibus griseis vestitus, scutello niveo, elytris fasciis duabus, transversis, obliquis, denudatis; rostro longitudinaliter concavo, irregulariter striato, prothorace lateribus subangulatim dilatato, utrinque impresso, medio canaliculato, remole granulato, elytris (disco profundius) punctato - striatis, basi, lateribus apiceque remote granulatis, disco transversim rugosis, margine apicali serrulat o, femoribus anticis modice incrassatis. - Long. 15 mill.

Mit Ausnahme der braunrothen Fühler, der Schenkel und des Krallengliedes ganz schwarz, mit graulich-weifsen, an den Seiten des Halsschildes dunkelgelben, an denen der Flügeldecken gelblichen, auf dem Schildchen schneeweifsen, haarförmigen Schuppen ziemlich dicht bekleidet, die Flügeldecken mit zwei schuppenfreien, etwas gebogenen Querbinden, von denen eine in der Mitte, die andern zwischen dieser und der Spitze. Der Rüssel seiner ganzen Länge nach ausgehöhlt und unregelmäfsig längsstreifig, die Stirn mit einer tiefen elliptischen Grube. Das Halsschild an den Seiten stark und fast eckig gerundet erweitert, daher breiter als lang, vorn und hinten eingeschnürt, in der Mitte der Länge nach gefurcht und jederseits mit einem seichten, rundlichen Eindruck, mit zerstreuten, glänzend-schwarzen Körnern besetzt, auf dem Rücken etwas weniger dicht behaart. Die Flügeldecken doppelt so breit als das Halsschild an der Basis und $3 \frac{1}{2}$ Mal so lang als dasselbe, bis weit hinter die Mitte parallelseitig, dann nach der Spitze zu verschmälert und an derselben gemeinschaftlich zugespitzt, auf der Scheibe grob, nach den Seiten und der Spitze zu feiner punktirt-gestreift, auf der Scheibe mit weitläufigen Querrunzeln, übrigens mit grofsen, glänzend - schwarzen, auf den Zwischenräumen fast in einer regelmäfsigen Reihe stehenden Körnern, der Seitenrand vor der Spitze körnig-gezähnelt. Die Vorderschenkel auffallend weniger verdickt als bei andern Arten. 
H. impressicollis: oblongus, niger, parce griseo-pubescens, rostro longitudinaliter concavo et ruguloso, antennis ferrugineis, fronte profunde foveolato, prothorace sat rotundato, triimpresso, granulato, intra basin et apicem transverse striato, scutello niveo squamoso, elytris punctato-striatis, interstitiis granulatis, margine apicali serrulato, femoribus anticis valde incrassatis. - Long. 11 mill.

Dem in den Sammlungen als gemmifer Reiche i. litt. bekannten Hadromerus recht ähnlich, doch mit Ausnahme des Schildchens ganz unbeschuppt und durch das eingedrückte Halsschild leicht zu unterscheiden. Schwarz, mit zerstreuten kurzen Haaren besetzt; die Stirn mit einer länglichen tiefen Grube, um welche sich gebogene Längsrunzeln bis an die Spitze des der Länge nach etwas concaven Rüssels hinziehen und hier nur eine dreieckige Stelle in der Mitte freilassen. Die Fühler rostroth. Das Halsschild fast anderthalb Mal so breit als lang, an den Seiten gerundet, hinten und vorn eingeschnürt und querstreifig, mit drei Eindrücken, von denen der mittlere hinten und vorn etwas tiefer und von einer nicht scharf eingeschnittenen Längsrinne durchzogen ist, übrigens mit zerstreuten glänzenden Körnern besetzt. Das Schildchen dicht weifs beschuppt. Die Flügeldecken kaum um ein Viertel breiter als das Halsschild, an der Spitze zusammen abgerundet, etwas unregelmäfsig punktirt gestreift, an der Basis, längs den Seiten und vor der Spitze mit erhabeneren, auf der Scheibe mit niedrigeren, meist zu leichten Querrunzeln zusammenfliefsenden Körnern besetzt, der Spitzenrand körnig gezähnelt. Die Unterseite mit längeren, mehr abstehenden Haaren, ein Fleckchen neben den Mittelhüften und die äufsere hintere Ecke der ziemlich dicht gekörnten Hinterbrust weifs beschuppt. Die vordersten Schenkel stark verdickt.

\section{Menetypus n. gen.}

Rostrum capiti aequale, paullo angustius, quadrangulare, supra planum, lateribus verticaliter inconspicuis.

Antennae scapo tenui, prothoracem non attingente, funiculi articulis $1^{\mathrm{mo}}$ et $2^{\mathrm{do}}$ obconicis, illo crassiore et paullo longiore, $3^{0}-$ $7^{\mathrm{mo}}$ globosis, $6^{\text {to }}$ reliquis vix, $7^{\mathrm{mo}}$ evidenter majore, clava ovali, acuita, triarticulata.

Oculi mediocres, parum convexi.

Prothorax subquadratus, lateribus rotundatus, basi apiceque angustatus et truncatus, pone oculos vibrissis instructus.

Scutellum parvum triangulare. 
Elytra oblonga, vix convexa, basi truncata, humeris obtusangulis, sutura postice subcarinata.

Pedes antici reliquis multo longiores femoribus valde incrassatis et tibiis leviter curvatis intus dentatis, postici tibiis corbulis apertis, instructi.

Abdominis segmentum primum inter coxas late rolundatum, postice medio leviter sinuatum, secundum primo paullo longius, quartum postice hians.

Den beiden Gattungen Pandeleteius ${ }^{1}$ ) und Hadromerus Schönherr's am nächsten stehend. Der Rüssel ist von der Länge des Kopfes, vierkantig, oben eben, mit einer Längslinie in der Mitte, die Seiten steil abfallend, so dafs, von oben gesehen, die Fühlergruben unter den Seitenkanten ganz verdeckt bleiben, während bei Pandeleteius die Seitenkanten stumpfer und die Fühlergruben von oben sichtbar sind. Die Augen verhältnifsmäfsig gröfser und schwächer gewölbt, als bei Pandeleteius. Die Fühler mit kurzem, feinem, den Hinterrand der Augen erreichenden, nur an der Spitze etwas angeschwollenen Schaft, das 1ste und 2te Geifselglied verkehrt-kegelförmig, das lste dicker und etwas länger als das 2te, das 3te bis 7 te kuglig gerundet, 3tes bis 5 tes gleich grofs, das 6 te kaum bemerkbar, das 7te deutlich dicker als die vorhergehenden, die Keule länglich, zugespitzt, dreigliedrig. Das Halsschild eben, an der Basis und Spitze gleichbreit, abgestutzt und vor derselben leicht eingeschnürt, die Seiten gerundet, vorn mit reichlichen Vibrissen hinter den Augen. Das Schildchen klein, dreieckig. Die Flügeldecken länglich, an der Basis gerade abgestutzt, mit stumpf vorragenden Schultern, hinter der Mitte am breitesten, hinten gemeinschaftlich zugespitzt, die Naht auf der Wölbung etwas kielig erhaben. Die Vorderbeine sehr lang, ihre Schenkel stark angeschwollen, ihre Schienen leicht gekrümmt und auf der Innenkante gezähnt, die Mittelbeine am kürzesten, die Körbchen der Hinterschienen offen, an den Tarsen das 3te Glied breit 2lappig, die Krallen frei und mäfsig klaffend. Das erste Abdominalsegment zwischen den Hinterhüften breit gerundet, an seinem Hinterrande in der Mitte seicht gebuchtet, das 2te Segment etwas länger als das 1ste, und viel länger als das 3te und 4te zusammen genommen, das 4te an seinem Hinterrande weit nach unten abklaffend, eine Eigenthümlichkeit, die auch den Hadromerus-Arten, wenn auch in geringerem Grade, zukommt.

M. hadromeroides: oblongus, supra fuscus, subtus obscurior, rostri apice, antennis pedibusque testaceis, breviter pubescens, 
dense griseo squamosus, disco elytrorum communi cervino-variegatus, capite prothoraceque punctis sparsis, nigris, piliferis, elytris punctato-striatis, interstitiis paullo convexis, punctis uniseriatis, nigris, piliferis. - Long. 4-5 $\frac{1}{2}$ mill.

In Umrifs und Gröfse ganz dem Pandeleteius hilaris ähnlich. Kopf, Halsschild und Flügeldecken heller oder dunkler braun, Spitze des Rüssels, Fühler und Beine bräunlich - gelb, nur die Spitze der Fühlerkeule und die Vorderschenkel mitunter dunkler. Die Pubescenz sehr kurz und niederliegend, nur auf der Wölbung der Flügeldecken länger und abstehend nach hinten gebogen. Das Schuppenkleid oben grauweifs, auf dem Rücken der Flügeldecken meist einen gemeinschaftlichen, mehr oder minder scharf abgegränzten, nach hinten zugespitzten, rehbraunen Fleck zeigend, auf dem Kopfe und dem Halsschilde dunkle, kurze, niederliegende Härchen, tragende Punkte freilassend. Die Flügeldecken punktirt-gestreift, die Zwischenräume leicht gewölbt und mit einer Reihe sehr kleiner Pünktchen besetzt, die bis zur Wölbung kurze, niederliegende, auf dieser längere, abstehende Härchen tragen. Die Unterseite fast schwarz und so wie die Schenkel und Schienen bald bläulichgrau, bald perlmutterglänzend, in der Mitte der Brust und des Hinterleibes manchmal goldglänzend beschuppt.

\section{Chamaelops nov. gen.}

Rostrum capile vix longius, sed angustius, antice altenuatum, quadrangulare, supra late impressum.

Antennae scapo extus ( $\sigma^{7}$ magis) incrassato, prothoracem vix attingente, funiculo gracili, articulis omnibus elongato-obconicis, subcylindricis, primo ceteris parum crassiore, secundo primo sesquilongiore, tertio primo aequali, 4-7 parum brevioribus.

Oculi oblongi, longitudinales, parum convexi.

Prothorax $\delta$ subquadratus, $\&$ longitudine fere duplo latior, basi profunde bisinuatus, lateribus usque ad medium parallelis, inde $\delta$ sensim, 오 subangulatim angustalus, antice truncatus et obsolete. elevato marginatus.

Scutellum triangulare.

Coleoptera ovalia, basi singulatim rotundato-producta, prothoracis basi multo latiora, humeris obtusangulis, lateribus vix ampliatis, apice conjunctim acuminatis.

Pedes femoribus modice incrassatis, tibiis anticis apice paullo incurvatis, corbulis posticarum cavernosis, glabris, tarsorum $1^{\text {mo }}$ et 
$2^{\mathrm{do}}$ angustis, primo latitudine sua apicali plus guam duplo longiore, unguiculis liberis.

Abdominis segmentum primum inter coxas rotundatum.

Nach Lacordaire's Anordnung ohne Zweifel den Cyphiden einzureihen, deren Vorderschienen von normaler Länge, deren Rüssel nicht auffallend länger als der Kopf, deren Klauen nicht verwachsen und deren Körbchen an den Hinterschienen gehöhlt und unbeschuppt sind; durch die an den Schultern stumpfeckigen Flügeldecken und die Form des Fühlerschaftes zunächst mit Plalyomus verwandt, von dem er sich aber durch den nach vorn versehmälerten Rüssel unterscheidet.

Geschlechtsunterschiede zeigen sich sowohl an den Fühlern und Beinen, als in der Form des Halsschildes und des Hinterleibes. Beim $\sigma^{\top}$ ist der Fühlerschaft viel auffallender nach der Spitze zu verdickt, die Behaarung der Beine, namentlich der vordersten, an der Innenseite der Schenkel und Schienen länger, das Halsschild relativ länger, von der Mitte an allmälig nach vorn verengt, beim 우 fast doppelt so breit als lang und von der Mitte aus fast unter einem stumpfen Winkel verengt, die Basis des Hinterleibs beim $\sigma^{\nearrow}$ eingedrückt, beim 오 nicht.

C. munitus: oblongus, niger, densissime squamosus et albido pubescens, fronte canaliculata et longitudinaliter striata, prothorace lineis tribus minus dense squamosis, inde obscurioribus, elylris subtiliter punctato-striatis, pedibus ferrugineis. - Long. 6-9 mill.

Schwarz mit rostrothen Beinen, dicht beschuppt und mit kurzer weifslicher Pubescenz versehen. Das Schuppenkleid grau, gelblichgrau, bräunlichgelb, kupferröthlich, zuweilen, namentlich an den Seiten und unten röthlichgolden, silberweifs und grünlich metallich schimmernd, auf dem Kopf und Halsschilde zerstreute, schwarze Punkte frei lassend, und aufserdem auf letzterem in der Mitte und auf beiden Seiten drei weniger dicht, manchmal kupfrig beschuppte, daher dunklere Linien bildend. Der Rüssel in seiner ganzen Breite vertieft, die Stirn eben, längsstreifig, mit einer bis zum Scheitel reichenden Mittelrinne. Das Halsschild dicht punktirt-gestreift, mit Ausnahme der Streifen ganz dicht beschuppt und pubescent, diese Pubescenz aus kurzen, wenig über die Schuppen hervorragenden, an den Seiten nach hinten gekrümmten, deutlichen weifsen Härchen bestehend. Die Unterseite aufser dem Schuppenkleide mit dünnen, feinen und längeren, weifsen Haaren besetzt. Die Schenkel schwach keulenförmig, ungezähnt, der Borstenkranz an der Spitze der Schienen gelb. 
Compsus deplanatus: oblongus, niger, breviter setulosus, squamulis fusco-canis, capite, lateribus el subtus albidioribus tectus; rostro sulcato, utrinque ante oculos canaliculato, prothorace scrobiculato, dorso deplanato, elytris apice breviter mucronatis, dorso deplanatis, punctato-striatis. - Long. $11 \frac{1}{2}$ mill.

Durch die eigenthümlichen, am Vorderrande des Halsschildes bis an die Wölbung der Flügeldecken reichende, fast gerandete $\mathrm{Ab}$ plattung leicht kenntlich. Schwarz, mit kurzen, zerstreuten Börstchen und dichten, bräunlich-grauen, auf dem Kopfe, an den Seiten und unten mehr weifslichen, hin und wieder (namentlich an den Beinen) mit kupferrothen gemischten Schuppen bekleidet. Der Rüssel mit einer breiten Längsfurche und jederseits derselben einer vom innern Augenrand bis zur Einfügung der Fühler reichenden Längsrinne. Die Fühler schwarz, der Schaft den Vorderrand des Halsschildes erreichend, nach seiner Basis zu kaum verdünnt, dicht weifs beschuppt und sowie die dicht und anliegend weifs behaarte Geifsel beborstet. Das Halsschild grobgrubig, auf dem Rücken scharfrandig abgeplattet. Die Flügeldecken mit kurzer, stumpfer, auswärts gerichteter Spitze, auf dem Rückeu bis fast zwei Drittel ihrer Länge in gleicher Ebene mit dem Halsschilde abgeplattet, der Rand der Abplattung verläuft, genau an der des Halsschildes sich anschliefsend, bis zur Mitte auf dem 4ten Zwischenraume und geht dann schräg nach hinten der Naht zu. Die Schienenkörbchen gehöhlt und beschuppt, an ihrem Rande gelblich beborstet.

C. bituberosus: oblongo-ovatus, niger, breviler setulosus, supra squamulis silaceo-incanis, subtus versicoloribus, dense tectus; rostro triangulariter impresso, utrinque fossula brevi ante oculos, prothorace medio late impresso, elytris grosse punctato-striatis, dorso transversim rugosis, apice breviter obtuse mucronatis, interstitiis tertio magis elevato et tuberculo pone medium instructo, quinto non nisi disco convexiore, septimo ab humero jam elevatiore. - Long. 11-15 mill.

In die Gruppe des placidus und canescens gehörig, durch die relativ kürzern und breitern Flügeldecken, sowie den ziemlich starken, aufrechten Höcker auf dem 3ten $\mathbf{Z}$ wischraum gut kenntlich. Schwarz, mit zerstreuten greisen Haaren und oberseits bräunlichgrauen, unten entweder eben so gefärbten oder grünlich-blauen oder kupferröthlichen mit kupferig-goldenen untermischten Schuppen bekleidet. Der Rüssel dreieckig eingedrückt, die Spitze des Dreiecks fast bis zur Stirngrube reichend, in dem Eindruck mit einem feinen Kielchen, was ebenso, wie das Grübchen, jederseits vor dem 
Auge nur nach Eutfernung der Schuppen deutlich sichtbar wird. Das Halsschild beim $\sigma^{\top}$ relativ schmäler als beim 우, grob runzeliggrubig, in der Mitte der Länge nach breit vertieft, die Vertiefung jederseits von einem Wulst begränzt. Die Flügeldecken bei den stumpfeckig vorragenden Schultern 1 $\frac{1}{4}$ Mal so breit als das Halsschild, hinter den Schultern bis dicht hinter die Mitte verbreitert, die Spitzen stumpfeckig divergirend, grob punktstreifig, auf dem Rücken leicht querrunzlig, die Zwischenräume convex, nur der 1ste bis zur Wölbung, der 2te ganz, der 4te, 5te und 6te an der Basis eben, der 3te, 5te und 7te und die Naht auf der Wölbung erhabener als die übrigen, der Höcker auf dem 3ten $Z_{\text {wischenraume am }}$ Anfange der Wölbung bald mehr, bald minder entwickelt. An den Schenkeln ist bei gut erhaltenen Exemplaren die Innenseite und ein Ring vor der Spitze mit silberweifsen, bläulichen, perlmutter-, goldoder kupferig-glänzenden Schuppen besetzt.

Exophthalmus crassicornis: oblongus, niger, capite, thorace, elytrorum lateribus et corpore subtus laete coeruleo squamosis, cingulo elytrorum basali fasciaque transversa flexuosa pone medium albo squamosis; rostro longitudinaliter convexo, antennis crassis, thorace disco remote ruditerque punctato, lateribus scrobiculato, elytris fossulato striatis. - Long. 18 mill.

Durch die ungewöhnlich dicken Fühler vor allen Arten der Gattung Exophthalmus (selbst nach der Lacordaire'schen Auffassung dersellsen) sich auszeichnend. Der Kopf am Scheitel und innen neben den Augen zerstreut - punktirt, der Rüssel der Länge nach gewölbt, glatt, jederseits mit einer kurzen Furche und zwischen dieser und der Fühlergrube mit zerstreuten groben Punkten. Der Fühlerschaft von der Basis an verdickt, an seiner Spitze und längs der Aufsenseite blau beschuppt, die ersten beiden Geifselglieder von gleicher Länge, das 3te wenig kürzer, das 4te bis 7 te nach und nach an Länge abnehmend und nach vorn mehr gerundet, alle verkehrt-kegelförmig und dicht mit haarförmigen bläulichen Schuppen bedeckt, die Keule etwas länger als die drei vorhergehenden Glieder zusammen, mattschwarz. Das Halsschild kaum breiter als lang, an der Basis zweibuchtig mit spitzen Hinterecken, an den Seiten bis vor die Mitte gleichbreit, von da nach vorn "etwa um ein Drittel verschmälert, vor dem Schildchen kurz gerinnt, auf der Scheibe zerstreut grob-punktirt, an den Seiten grofsgrubig. Die bläuliche Schuppenbekleidung bildet jederseits der breiten, fast nackten Mitte eine dichtere Längsbinde, die sich beiderseits über den Kopf bis zur Spitze des Rüssels fortsetzt, aufsen neben derselben stehen die 
Schuppen so entfernt, dafs die schwarze Grundfarbe vorherrscht, an den Seiten aber wieder sehr dicht. Die Flügeldecken grubig punktirt-gestreift, einzeln zugespitzt, auf dem Rücken aufser den Zeichnungen fast schuppenlos, an den Seiten und der Spitze dicht bläulich beschuppt, ein Streifen, der die Naht, die Basis und den Seitenrand unter dem Schulterhöcker herum bis zu ein Drittel der Flügeldeckenlänge begleitet und von da als gebogene Querbinde wieder zur Naht geht und somit einen fast regelmäfsigen Ring bildet, sowie eine gebogene Querbinde hinter der Milte aus weifsen runden und schmalen etwas aufstehenden Schuppen gebildet, die äufserste Spitze mit kurzen dunkeln Schuppen besetzt. Die Unterseite mit den Beinen dicht bläulich beschuppt und weifs behaart, neben den Vorderhüften eine breite weifse Binde, die Schienen an ihrer Innenkante mit einer Reihe schwarzer Borsten, an den hintersten in geringerer $\mathrm{Zahl}$ als an den vordern.

$$
\text { Prepodellus nov. gen. }
$$

Rostrum capite sesquilongius et angustius, postice obtusangulum, ante insertionem antennarum paullo dilatatum, apice non emarginatum, supra planum, medio leviter canaliculatum. Scrobes antennarum ab oculis remotae, anterius jam descendentes.

Antennae subterminales, scapo oculorum medium attingente, funiculi articulis duobus breviter obconicis, primo crassiore, reliquis subtransversim globosis, clava breviter ovali, acuminata.

Oculi parum convexi.

Prothorax antice posticeque truncatus, subcylindricus vel paullo transversus.

Scutellum minutissimum, punctiforme.

Elytra subparallela vel oblonga, basi thorace evidenter latiora, humeris obtusangulis, subnavicularia, apice conjunctim acuminata.

Pedes femoribus parum clavatis, tibiis rectis, anticis apice intus paullo sinuatis sed muticis, corbulis posticarum cavernosis, glabris, tarsis brevibus, articulo tertio late bilobo, unguiculis liberis.

Abdomen segmento ultimo transverso.

Unter die Gruppe der Cyphiden gehörig und durch den längeren Rüssel und die freien Klauen in die Nachbarschaft von Eustales und Exophthalmus gewiesen, von welchen beiden die Gattung Prepodellus am auffälligsten durch die Form des Rüssels, der Fühlergeifsel und des letzten Hinterleibssegments abweicht.

Der Rüssel mindestens anderthalb Mal länger als der Kopf, von den Augen bis zur Einlenkung der Fühler parallel und stumpf 
vierkantig, die Seiten steil abfallend, so dafs die Fühlergruben von oben nicht sichtbar sind, bei den Fühlern durch das Hervortreten der untern Grubenkante etwas breiter werdend, an der Spitze nicht ausgerandet, oben eben, mit einer schwach vertieften Mittellinie; die Fühler mäfsig lang, ihr Schaft die Mitte der schwach gewölbten Augen erreichend, die ersten beiden Glieder der Geifsel kurz kegelförmig, das erste viel dicker, aber nicht länger als das zweite, die übrigen kuglig, kaum etwas breiter als lang, nach der Keule zu dicker werdend, diese kurz oval, zugespitzt. Das Halsschild vorn und hinten abgestutzt, nach vorn wenig verengt, an den Seiten melir oder wenig gerundet. Das Schildchen punktförmig. Die Flügeldecken an der Basis deutlich breiter als das Halsschild, mit stumpfeckig vorragenden Schultern, ziemlich geraden oder ein wenig gerundeten Seiten, hinten gemeinschaftlich zugespitzt. Die Beine mit schwach keulig verdickten Schenkelh und geraden Schienen, nur die vordersten an der Innenkante vor der Spitze ausgebuchtet, daher die Innenecke vorgezogen, aber ohne Haken, die Körbchen der Hinterschienen gehöhlt und unbeschuppt, die Tarsen verhältnifsmäfsig kürzer als bei den verwandten Gattungen, das 3te Glied breit zweilappig, das Klauenglied lang mit getrennten Klauen. Das letzte Hinterleibssegment an der Basis doppelt so breit als lang, mit gerundeten Seiten.

P. nigriclavis: ferrugineus, clava antennarum nigra, griseo albido (subtus densius) squamosus, setosus, setis longis furcatis; rostro capite sesquilongiore, prothorace subcylindrico. - Long. 3 mill.

Ischnodes setiferus Jekel in litt.

Rostroth, der Scheitel, das Halsschild und die Brust etwas dunkler, nur die Fühlerkeule schwarz, mit graulich oder grünlich weifsen, auf dem Rücken rundlichen, an den Seiten und unten länglichen Schuppen nicht sehr dicht bedeckt, und auf dem Kopfe und Halsschilde kurz beborstet. Der Rüssel anderthalb Mal so lang als der Kopf; das Halsschild so lang als breit, nach vorn kaum ver engt, an den Seiten kaum gerundet. Die Flügeldecken punktirt-

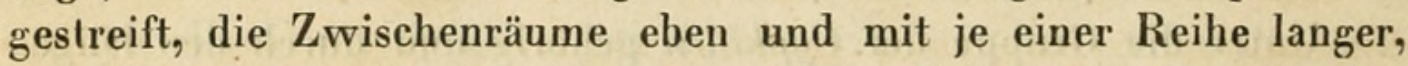
aufrechter, nach oben verdünnter, an der Spitze selbst zweispaltiger, weifslicher Borsten beselzt. Die schalgelben Beine sind weifslich behaart und unbeschuppt.

P. ruficornis: ferrugineus, griseo albido (subtus densius) squamosus, dorso variegatus, setosus, setis brevioribus, inclinatis, 
apice dilatatis; rostro capite fere duplo longiore, prothorace subtransversus. - Long. 3 mill.

Ebenso gefärbt wie der vorige, nur ist die Fühlerkeule ebenfalls roth; graulich oder gelblich weifs beschuppt, die Schuppen oben rundlich und sparsamer, an den Seiten und unten länglicher und dichter, auf dem Rücken der Flügeldecken eine bisweilen recht scharf hervortretende Zeichnung, bestehend aus einem kurzen Strich

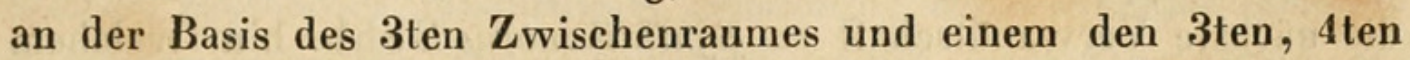
und 5ten Zwischenraum einnehmenden Fleck vor der Mitte aus weifseren Schuppen gebildet. Der Rüssel fast doppelt so lang als der Kopf, wie die Stirn, kurz beborstet. Das Halsschild in der Mitte breiter als lang, an den Seiten gerundet, nach vorn etwas mehr verengt als nach hinten, hinter dem Vorderrande schwach eingeschnürt, oben leicht gewölbt, mit kurzen, nach vorn niedergebogenen Borsten reichlich besetzt. Die Flügeldecken punktirt-gestreift, die ebenen $\mathbf{Z}_{w}$ ischenräume mit je einer Reihe kurzer, an ihrer Spitze verbreiteter und abgestutzter, nach hinten geneigter Borsten. Die Beine wie beim vorigen.

\section{Bothinodontes nov. gen.}

Rostrum capite sesquilongius et angustius, quadrangulare, apicem versus parum dilatatum, ante oculos utrinque foveola parva oblonga insculptum, verticaliter visum medio utrinque acute incisum, scrobes antennarum praecipiles.

Antennae scapo prothoracis marginem anteriorem superante, apice tumidulo, funiculi articulis duobus primis elongato obconicis, primo vix longiore et crassiore, reliquis aequalibus breviter obconicis, clava ovali acuminata.

Oculi rotundati, vix convexi.

Prothorax antice posticeque truncatus, lateribus parum rotundatus, antice paullo angustior, supra vix convexus, granulatus et tuberculatus.

\section{Scutellum minutissimum.}

Coleoptera breviter ovalia, usque ad medium sensim duplo dilatata, dein apicem versus fortiter angustata, basi thorace non latiore, truncata nec marginata. dorso plana, postice declivia.

Pedes femoribus pedunculatis, fortiter clavatis, tibiis anticis apice leviter intus arcuatis et mucronatis, medio intus perpaullo dilatatis, corbulis posticarum cavernosis, glabris, tarsis articulis duobus primis aequalibus, tertio multo angustioribus, unguiculis liberis hiantibus. 
Metasternum breve, postice medio profunde foveolatum.

Abdomen suturis sat profundis, segmento primo inter coxas lato, vix rotundato, apice medio elevato.

Die gehöhlten Körbchen der Hinterschienen, die an den Schultern völlig abgerundeten Flügeldecken, die kurze Hinterbrust und die Eindrücke auf dem Rüssel jederseits vor dem Auge deuten auf die 2te Gruppe der Geonomiden und die Form der Schenkel auf die nächste Verwanđtschaft zu Synthlibonotus Schh. hin, welchem sich auch Bothinodontes in der allgemeinen Form recht gut anschliefst, von welchem er sich aber schon durch die Form des Rüssels leicht unterscheidet. Derselbe ist anderthalb Mal so lang und schmäler als der Kopf, stumpf vierkantig, die obere Fläche der Länge nach vertieft, etwas schmäler als die untere, so dafs von oben gesehen die Seitenflächen sichtbar sind und die Stelle, an der die Fühlergruben die untere Kante schneiden, als Einschnitt erscheint, dessen hintere Begränzung (obere Kante der Fühlergrube) scharfeckig ist, von hier nach der Spitze zu ein Wenig breiter, indem die Pterygien etwas vortreten, an der Spitze eben, dreieckig ausgeschnitten, vor jedem Auge nach innen ein deutlicher Längseindruck. Der Schaft der Fühler den Vorderrand des Halsschildes überragend, die ersten beiden Geifselglieder länglich, verkehrt - kegelförmig, das erste kaum länger und dicker als das zweite, die übrigen gleichlang, kurz verkehrt-kegelförmig. Das Halsschild vorn und binten gestutzt, an den Seiten schwach gerundet, über die Mitte so breit als lang, nach vorn etwas mehr verengt als nach hinten, oben kaum gewölbt. Die Flügeldecken an der Basis abgestutzt, nicht gerandet, an den Schultern völlig abgerundet (während bei Synthlibonotus die Schulterecke immer noch angedeutet ist) kaum um ein Viertel länger als über die Mitte breit, hier doppelt so breit als an der Basis, oben bis zum 7ten Zwischenraum etwas verflacht. Die Beine kürzer als bei Synthlibonotus, die stark keuligen (an den Vorderbeinen unten fast stumpfeckigen) Schenkel noch dünner und länger gestielt, als bei dieser Gattung, die Vorderschienen an ihrer Innenkante in der Mitte etwas verbreitert, an ihrer Spitze schwach einwärts gebogen und mit einem kleinen Hornhaken versehen, die Körbchen der Hinterschienen gehöhlt und unbeschuppt, an den Tarsen die ersten beiden Glieder ziemlich gleichlang, viel schmäler als das 3te, die Krallen frei und weit auseinander klaffend. Die Vorderhüften zusammenstofsend, die Mittelhüften schmal getrennt, die Hinterbrust kurz mit einem tiefen Grübchen vor ihrem Hinterrande in der Mitte, der Fortsatz des ersten 
Hinterleibssegments zwischen den Hüften sehr breit, vorn kaum gerundet, fast gestutzt, in der Mitte des Vorderrandes etwas aufgetrieben, die Nähte zwischen den mittleren Segmenten tief und gerade, die Segmente kaum gewölbt.

B. squalidus: breviter obovatus, fuscus, antennis pedibusque ferrugineis, supra fusco griseo squamosus, subtus parce griseo pubescens, prothorace canaliculato, granulato, disco utrinque tuberculis duobus humilibus, elytris punctato-striatis, interstitiis planis, setulis apice dilatatis griseis una serie, tertio basi tumido. - Long. 5 mill.

Kurz verkehrt-eiförmig, dunkelbraun, der Hinterleib etwas heller, die Fühler und Beine rostroth; oben schmutzig graubraun beschuppt, unten spärlich greis behaart. Das Halsschild gekörnt, mit einer Mittelrinne und 4 niedrigen Höckerchen auf der Scheibe, von denen die beiden vordern etwas weiter von einander entfernt sind, als die hinteren. Die Flügeldecken punktirt-gestreift, mit einer Reihe kurzer, an ihrer Spitze verbreiterter, nach hinten geneigter, greiser Börstchen auf den flachen $\mathbf{Z}$ wischenräumen, deren dritter an der Basis etwas aufgetrieben erscheint. 


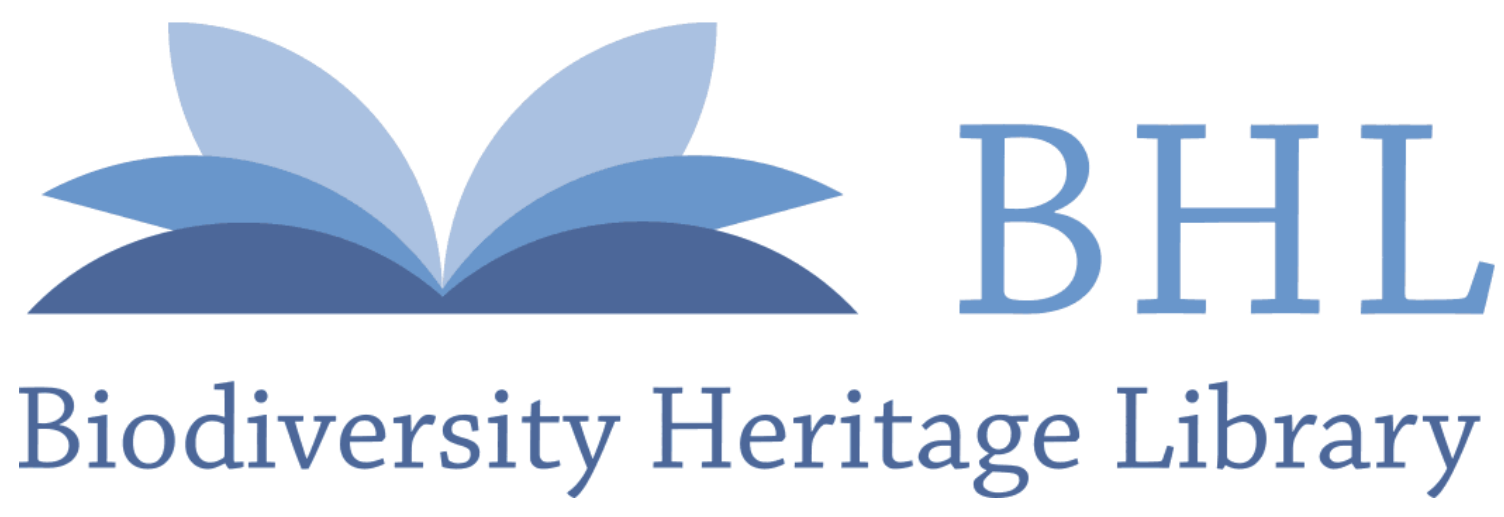

Kirsch, Theodor Franz Wilhelm. 1867. "Beiträge zur Käferfauna von Bogotà." Berliner entomologische Zeitschrift / herausgegeben von dem Entomologischen Vereine in Berlin 11(3ロ4)215-243. https://doi.org/10.1002/mmnd.18670110303.

View This Item Online: $\underline{\text { https://www.biodiversitylibrary.org/item/36408 }}$

DOI: https://doi.org/10.1002/mmnd.18670110303

Permalink: https://www.biodiversitylibrary.org/partpdf/210205

\section{Holding Institution}

Smithsonian Libraries

\section{Sponsored by}

Smithsonian

\section{Copyright \& Reuse}

Copyright Status: Public domain. The BHL considers that this work is no longer under copyright protection.

This document was created from content at the Biodiversity Heritage Library, the world's largest open access digital library for biodiversity literature and archives. Visit BHL at https://www.biodiversitylibrary.org. 